\title{
Peptide hydrogels - versatile matrices for 3D cell culture in cancer medicine
}

\author{
Peter Worthington ${ }^{1,2}$, Darrin J. Pochan ${ }^{3}$ and Sigrid A. Langhans ${ }^{1 *}$ \\ ${ }^{1}$ Nemours Center for Childhood Cancer Research, Alfred I. duPont Hospital for Children, Wilmington, DE, USA \\ ${ }^{2}$ Department of Biomedical Engineering, Delaware Biotechnology Institute, University of Delaware, Newark, DE, USA \\ ${ }^{3}$ Department of Materials Science and Engineering, Delaware Biotechnology Institute, University of Delaware, Newark, DE, USA
}

Edited by:

Victoria Virador, Virador and

Associates, USA

\section{Reviewed by:}

Carmelo Nucera, Harvard Medical

School, USA

Seunghyung Lee, Temple University

School of Medicine, USA

\section{${ }^{*}$ Correspondence:}

Darrin J. Pochan, Department of Materials Science and Engineering, University of Delaware, 201 DuPont Hall, Newark, DE 19716, USA

e-mail: pochan@udel.edu;

Sigrid A. Langhans, Nemours Center for Childhood Cancer Research, Alfred I. duPont Hospital for Children Rockland Center I, 1701 Rockland Road, Wilmington, DE 19803, USA e-mail:

langhans@nemoursresearch.org
Traditional two-dimensional (2D) cell culture systems have contributed tremendously to our understanding of cancer biology but have significant limitations in mimicking in vivo conditions such as the tumor microenvironment. In vitro, three-dimensional (3D) cell culture models represent a more accurate, intermediate platform between simplified 2D culture models and complex and expensive in vivo models. 3D in vitro models can overcome 2D in vitro limitations caused by the oversupply of nutrients, and unphysiological cell-cell and cell-material interactions, and allow for dynamic interactions between cells, stroma, and extracellular matrix. In addition, 3D cultures allow for the development of concentration gradients, including oxygen, metabolites, and growth factors, with chemical gradients playing an integral role in many cellular functions ranging from development to signaling in normal epithelia and cancer environments in vivo. Currently, the most common matrices used for 3D culture are biologically derived materials such as matrigel and collagen. However, in recent years, more defined, synthetic materials have become available as scaffolds for 3D culture with the advantage of forming well-defined, designed, tunable materials to control matrix charge, stiffness, porosity, nanostructure, degradability, and adhesion properties, in addition to other material and biological properties. One important area of synthetic materials currently available for 3D cell culture is short sequence, self-assembling peptide hydrogels. In addition to the review of recent work toward the control of material, structure, and mechanical properties, we will also discuss the biochemical functionalization of peptide hydrogels and how this functionalization, coupled with desired hydrogel material characteristics, affects tumor cell behavior in 3D culture.

Keywords: three-dimensional cell culture, hydrogel, functionalization, cancer, matrix

\section{INTRODUCTION}

\section{HISTORY OF CANCER MODELS}

Over the past decades, fundamental biological research and translational and clinical studies have tremendously increased our understanding of cancer, transforming it from a poorly understood and mostly deadly disease into one with ever evolving therapeutic options and increasing survival rates. While a large variety of cancer models is available, spanning from cells cultured in a monolayer $(1,2)$, to cells cultured within a complex substrate, to animal models (3), and, ultimately, human cancer tissues and clinical trials (4), much of our understanding of cancer has resulted from research on cultured cells utilizing various cell models $(5,6)$. As each model has its own set of advantages and disadvantages, the best choice often becomes a tradeoff between simplicity of setup vs. clinical transfer of results to human patients (7).

The growing range of cancer model options available today was not available at the turn of the 19th to the 20th century. One of

Abbreviations: 2D, two-dimensional; 3D, three-dimensional; ECM, extracellular matrix; Fmoc-FF, fluorenylmethoxycarbonyl-diphenylalanine; Fmoc-RDG, fluorenylmethoxycarbonyl arginine-glycine-aspartic acid; HA, hyaluronic acid; PEG, polyethylene glycol. the earliest tumor models created was designed by Carl Jensen (8), where he transplanted mouse sarcomas into healthy mice and measured tumor growth to estimate the vitality of the transplanted cancer. This type of tumor transplantation would continue as the primary animal model until the 1980s, with the creation of transgenic mice and the ability to readily develop in vivo cancer models with specific gene mutations (9). In addition to the early animal cancer models, stable cancer cell lines were first developed starting in the 1950s with Hela cells being the most commonly used and oldest cancer cell line available (10). These immortalized cell lines allowed for prolonged, controlled cellular studies when cultured in glass Petri dishes or, more recently, on tissue culture polystyrene. However, while monolayer cultures undoubtedly have played and still play a crucial role in cancer research, there remains a vast jump in complexity from two-dimensional (2D) cell cultures to animal models often resulting in clear differences between experimental findings and clinical reality (11).

Beginning in the early 1980s, researchers began to address the large differences between 2D cell culture and the in vivo environment by adding more intricacy to $2 \mathrm{D}$ cell culture with testing the effects of new substrate materials on cells in culture (12-14). It is now well accepted that $2 \mathrm{D}$ cultures can show large differences in 
cell phenotype by controlling the cell culture scaffold. For example, on 2D hyaluronic acid (HA) scaffolds, changing the elasticity of the matrix through crosslinking or adding collagen ligands affected the organization of the actin cytoskeleton (15). Another study showed that matrix stiffness controlled stem cell differentiation and lamin levels (16). Hydrophobicity of the scaffold was shown to control adhesion of cells to the matrix and ultimately what phenotypes the cells display (17). Additional complexity can be added by growing cells in vitro in three-dimensional (3D) matrices. Culturing cells within a $3 \mathrm{D}$ substrate is a relatively new culture method that seeks to combine the simplicity of in vitro cell culture with creating results more relevant to a $3 \mathrm{D}$ in vivo environment while also helping to minimize the costs and variability associated with animal models (18). This will be of particular interest in the development of new lead compounds for cancer therapy by high-throughput screening (HTS) of small molecule libraries. While HTS remains a promising step in cancer drug development, its value has been limited as prediction of the clinical success of new drug candidates proved to be difficult (19). One of the reasons for this lack of reliability to predict in vivo efficacy has often been ascribed to the fact that most HTS screenings are done using traditional 2D cultures of cancer cells. While 2D cultures are convenient and can easily be automated, new 3D matrices are well suited to provide more physiological and thus predictive platforms for HTS and drug discovery in cancer.

\section{ADVANTAGES OF 3D CELL CULTURES}

When comparing 2D and 3D cell cultures at a cursory level, it should seem clear that $3 \mathrm{D}$ cell constructs are more true to in vivo conditions as tissues and tumors are 3D structures of extracellular matrix (ECM) and multiple cell types that interact in a complex manner rather than being a simple monolayer or a series of stacked cellular monolayers $(20,21)$. In a $3 \mathrm{D}$ environment, cells respond differently to stimuli as compared to $2 \mathrm{D}$ monolayers because of multiple variables in the environment surrounding the cells (22) and the material that constitutes the scaffold (e.g., protein, synthetic polymer, or a combination of the two) has a large impact through its properties such as density (23), porosity (24), and stiffness $(25,26)$. Chemical functionalities in $3 \mathrm{D}$ scaffolds can also affect cell behavior and the density of attachment ligands controls the amount of focal adhesions in a cell. While in monolayers, these focal adhesions are limited to the interactions of the basal membrane with the surface of the tissue culture dish; these interactions encompass the entire cell surface in a $3 \mathrm{D}$ matrix $(27,28)$. Such cell-matrix interactions often result in differences in cell morphology within a 3D matrix. For example, in gelatin hydrogels, cell alignment and elongation can be controlled (29).

Another significant difference between 2D and 3D environments is the availability of small molecules such as glucose, amino acids, and other growth factors that are usually added to culture medium and that of oxygen. In 2D monolayers, usually all cells have direct access to these nutrients; while in 3D cultures, the availability of small molecules depends on diffusion rates and local environments within the scaffold (30). This results in concentration gradients throughout the matrix that can more closely mimic a tissue environment with cells encapsulated further from the media having decreased exposure to additives and oxygen
(31). Such chemical gradients can be responsible for various cell responses including differentiation and oxygen gradients are particularly important in tumor development (32). 3D cultures also allow for the formation of spheroids that are instrumental to many cancer cell studies including breast cancer (33). Such spheroids have been shown to have an LD50 value much closer to in vivo values, which may explain the lack of in vivo efficacy often found in drug development that relies on 2D monolayers (34).

In vivo cells exist in a complex aqueous $3 \mathrm{D}$ environment encompassing primarily proteins and polysaccharides. The cells interact with their environment by binding to these proteins thereby activating signaling pathways that crosstalk with growth factor signaling cascades to integrate environmental cues. For example, matrix signals contribute to the integrin-mediated control of mesendoderm differentiation in which specific matrix glycans govern cell fate (35). Cancer cells are adept at altering their microenvironment to promote tumor growth and metastasis. In the case of thyroid cancer harboring the BRAF mutation, the mutation promotes upregulation of genes associated with ECM remodeling, resulting in a more aggressive cancer $(36,37)$. Each facet of the microenvironment helps to control and direct cell fate $(38,39)$, and consideration of the optimal scaffold for $3 \mathrm{D}$ cell culture is of paramount importance as it will directly affect the phenotype and behavior of cells in culture. An exciting new application will be the modeling of tumor angiogenesis and evaluation of the angiogenic capability of tumor cells in 3D (40). While there are various matrix supports available to recreate complex culture environments due to their unique ability to recapitulate a realistic in vivo environment, hydrogels have been the overwhelming choice for use in $3 \mathrm{D}$ cell culture.

\section{HYDROGELS AS 3D CELL CULTURE SCAFFOLDS}

A hydrogel is a dilute polymer or supramolecular network with given structure and network properties obtained by intermolecular crosslinks in the case of a polymer molecular network or by interfibrillar crosslinks in the case of supramolecular fibrillar hydrogel networks $(41,42)$. A hydrogel is mostly water, usually defined as over $95 \%$ by volume, but the material displays solidlike material properties in the quiescent state (43). Hydrogels are ideal materials to use as $3 \mathrm{D}$ cell culture scaffold because of the similarities in material properties and, when properly designed, the similarities in biological properties to the ECM (43). A common example of a hydrogel is gelatin, a protein mixture derived from cleaving collagen that is used in many different processes; including cooking, photography, and pharmaceuticals. For use in cell culture, there are multiple types of gelatin depending on the collagen source, which have different mechanical properties (44). When comparing porcine and piscine gelatin, there are similarities due to their base collagen being alike but the different ratios of amino acids result in piscine gelatin being weaker rheologically and having a lower melting temperature (45).

For the purpose of this review, hydrogels will be categorized by their source, biologically or synthesized, and by their material, naturally occurring or by human design. Natural hydrogels are those that are found in nature, and are taken from a biological source, and include collagen, matrigel, which constitute ECM proteins and alginate that originates from cell walls of algae. Due to 
their natural source, they are usually biocompatible. On the other hand, they are complex and ill-defined scaffolds that are difficult to tune mechanically.

There are multiple types of synthetically produced hydrogel scaffolds including non-natural polymers like polyethylene glycol (PEG) (46) and natural polymers like the polysaccharide HA (4749). Unnatural synthesized polymer hydrogels have the advantage that they are usually easy to tune by controlling material aspects either through synthesis or crosslinking. They are also comparatively inexpensive and the material is reproducible and shows consistent results. However, the lack of biological moieties may be a shortcoming when attempting to reproduce natural EMC but biological peptides often can be cross-linked to the scaffold to improve functionality $(50,51)$. Like synthetic polymers, natural synthesized polymers share advantages in regard to material tunability and batch-to-batch consistency with reproducible results (52-54). Natural synthesized hydrogels can also be highly biocompatible because of the biological nature of the base material requiring less frequently functionalization as biological moieties are part of the primary chain. Unfortunately, the material cost can be high depending on the type of synthesis required.

\section{CURRENT STANDARD NATURAL CELL CULTURE HYDROGELS}

Hydrogel materials made from natural proteins, for example collagen and matrigel, are a common choice as $3 \mathrm{D}$ cell culture scaffolds due to their biocompatibility, adhesive properties, and inclusion of growth factors, often resulting in cellular phenotypes typically seen in vivo, including spheroid formation, controlled differentiation, and directed growth.

\section{COLLAGEN}

Collagen is a fibrillar protein made of three alpha helices coiled together into a triple helix. It is the most abundant protein in humans and provides for structure and function in the ECM, making it a logical choice as an in vitro cell culture scaffold (55-57). Cells attach to collagen through integrins thereby activating cell signaling pathways that control cell survival (58), cell growth, and differentiation (59). The cellular phenotype of cells grown in collagen may differ vastly from monolayer cultures. For example, Madin-Darby canine kidney (MDCK) cells grow in 2D cultures as tight monolayers but form spheroids in collagen (60). Changes in collagen nanostructure can control morphology and the osteogenic potential of cells in culture (61), while changes in collagen stiffness can alter fibroblast proliferation (58). Collagen has also been seen to improve survival outcomes for cell transplants into rats (58).

\section{MATRIGEL}

Matrigel is a collection of proteins and growth factors extruded from Englebreth-Holm Swarm mouse tumors (13). It is mainly made of the proteins collagen, laminin, and enactin, but also includes multiple growth factors like basic fibroblast growth factor, epidermal growth factor, insulin like growth factor, transforming growth factor beta, platelet derived growth factor, and nerve growth factor (62). Because it is produced from excreted ECM and has been minimally processed, Matrigel is a good mimic of in vivo cellular conditions to study cellular phenotypes $(63,64)$.
For example, breast cancer cells cultured on matrigel are more susceptible to drug treatment compared to monolayer cultures (11), and macrophages can be induced to express endothelial lineage markers in an angiogenic environment with matrigel (65).

While naturally derived collagen and matrigel hydrogel materials show success for many cell culture conditions, there is significant room for improvement of the materials for 3D culture. Some of the limitations of biologically derived materials result from the manufacturing process from live tissue, resulting in a complex, chemically not well-defined scaffold consisting of more than 1800 proteins $(62,66)$. The presence of multiple growth factors together with batch-to-batch variability of the purified scaffold may interfere with biological studies of signaling pathways or pharmacological investigations on drug-induced effects (67). To overcome this obstacle, growth factor-reduced matrigel has been developed for applications requiring a more highly defined basement membrane preparation, whereas high concentration matrigel appears to be better suited for in vivo applications. A study comparing the two scaffolds using patients' degenerative disk cells found that cells grown on top of either scaffold displayed similar phenotypes, but the proliferation rate was higher for cells grown on the reduced growth factor scaffold (68). However, an ill-defined hydrogel material cannot be approved for human implantation leading to road blocks in translating basic research into clinical applications. Thus, there is clearly a need for new materials with the biological functionality of naturally occurring ECM and the capability of designing specificity in biological and material properties (69). Synthetic hydrogel materials are ideally suited to address these limitations.

\section{ESTABLISHED AND UPCOMING SYNTHETIC PEPTIDE HYDROGELS}

The evolving field of small peptide-based hydrogel materials allows for material definition and design applicable for future clinical biomedical efforts and provides new scaffolds for $3 \mathrm{D}$ cell culture to address important questions in cell biology, drug delivery/discovery, and tissue engineering. The molecules, while diverse in primary structure, have a similar, general design. The peptides tend to be amphiphilic, relying on intramolecular folding and intra- and intermolecular physical interactions, controlled by $\mathrm{pH}$ and salt, for gelation through intermolecular assembly. Most final hydrogel materials also have a nanofibrillar structure. One major advantage of using synthetic peptides is the ease by which alterations can be introduced into the hydrogel scaffold by amino acid substitution/addition (both natural and non-natural), extension/shortening of the peptide sequence, or functional epitope addition at the termini of peptide chains or as side chains to a peptide sequence (70-73). Thus, the peptides described in the following chapter in fact represent a family of peptides with a basic structure, and if applicable, additional functional alterations. Each section will examine different short sequence amino acid hydrogels families, their unique characteristics, advantages and disadvantages, and potential as a $3 \mathrm{D}$ cell culture scaffold. The peptides being presented have been around for varying amounts of time. The older more established peptides have been used to culture a variety of cell lines including cancer cells and have undergone several functional alterations to improve culture conditions. The 
more recently developed peptides are not as well characterized and some were originally developed as a drug delivery vehicle and are only now being discovered as suitable 3D culture scaffolds. Despite the fact that some of these hydrogels have not yet been used for the culture of cancer cells, we decided to include these peptides in this review. They should not be overlooked as they show great promise for future applications in cancer research, including modeling of the tumor microenvironment, enrichment of cancer stem cells and drug discovery. For example, while HTS remains a promising initial step in building new classes of lead compounds, and particularly in cell line models for cancer, its value is limited in predicting clinical effectiveness. One of the reasons for this lack of reliability to predict in vivo efficacy has often been ascribed to the fact that most HTS screenings were done using traditional 2D cultures of cancer cells. While 2D cultures are convenient and can easily be automated, compelling evidence suggests that cells cultured in non-physiological 2D conditions differ from cells grown in the more in vivo like 3D systems. Thus, a 3D culture model is expected to be a better platform for drug discovery and is likely more predictive of efficacy of potential drugs for future preclinical studies and clinical trials. Collagen or matrigel are commonly used 3D matrices that provide an in vivo like environment. However, due to their natural origin, the batch-to-batch variation is considered a major hindrance to obtain reproducible results. Natural matrices also limit the possibility of mimicking different tissue environments as they only have limited capabilities for their chemical and mechanical properties to be modified. Synthetic peptide hydrogels can overcome these limitations and can provide an optimized biologically active cell environment with tunable porosity, permeability, and mechanical stability. Synthetic matrices not only offer more defined properties than matrices obtained from natural resources but also allow for controlling of adhesive moieties (e.g., functionalization with RGDS peptides), controlled inclusion of proteolytic sites, and defined mechanical properties such as material stiffness and pore size to enhance nutrient exchange and improve cell proliferation. While HTS screening in 3D cultures is still in its infancy, it is one of the most promising applications of synthetic peptide hydrogels.

\section{EAK16 AND RADA16}

EAK16 is an amphiphilic peptide and was one of the earliest peptide hydrogels used for cell culture (74). Its amino acid sequence, AEAEAKAKAEAEAKAK (Figure 1), was discovered in yeast (75), and subsequently a second peptide designated RADA16 was developed based on reproduction of the molecular interactions that

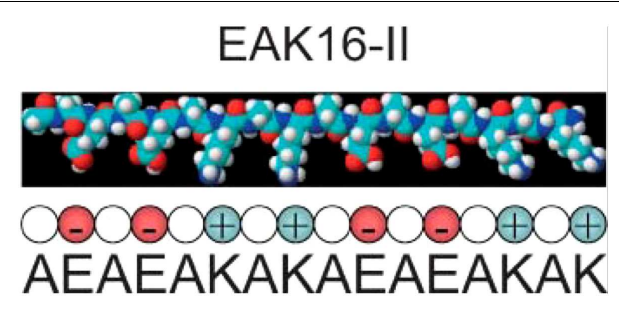

FIGURE 1 |The EAK16 sequence. Reprinted with permission from Ref. (81). Copyright 2004 Biophysical Society. cause EAK16 to gel. These gels initially were utilized as a substrate for $2 \mathrm{D}$ cultures and have been used for quite a variety of cell types including HIT-T15, CEF, HFF, HepG2, MG63, Hela, HEK293, 3T3, PC12, and SH-SY5Y cells (76). A typical protocol for a culture setup includes mixing of the peptide solution with culture medium and allowing the mixture to dry overnight. Plating the cells on top of the substrate enables standard cell culture procedures, proliferation assays, and fluorescence microscopy (76). EAK16 was subsequently also developed into a true 3D culture model, where a cell/sucrose suspension was mixed directly with the peptide solution creating a cell encapsulated gel (77). RADA16 was used for a 3D ovarian cancer model to study cell invasion and drug resistance. When compared to $2 \mathrm{D}$ cultures, the RADA16 cell system showed stronger resistance to anticancer agents, curcumin and paclitaxel (73). In a different study, RADA16 was used as a vehicle to deliver Schwann cells to rat spinal cord injuries, and the RADA16 group showed the biggest improvement in mobility as measured by the Basso Beattie and Bresnahan test (78). A similar study used RADA16 functionalized with IKVAV, a sequence derived from laminin, to deliver neural stem cells to traumatic brain injury in rats. Greater cell proliferation was shown using RADA16 and the ability to direct cell differentiation fate with the functionalized matrix caused more mature neurons to form (79). While these are promising results, the major disadvantage of EAK16 and RADA16 are their mechanical properties. The stiffness is very low compared to natural tissue resulting in a lack of appropriate rheology. Groups have attempted to increase stiffness by adding functional groups with some success. A notable example was the addition of GPGGY to RADA16, an amino acid sequence inspired by a protein in spider silk (80).

\section{Fmoc-FF AND Fmoc-RDG}

Fluorenylmethoxycarbonyl-diphenylalanine (Fmoc-FF) and fluorenylmethoxycarbonyl arginine-glycine-aspartic acid (FmocRDG) form hydrogels based on aromatic interactions (82-84) and have been successful as a scaffold for cell culture $(85,86)$. The hydrogel is a relatively simple gelator relying on a few peptides and Fmoc groups and is formed by pi-pi staking between the Fmoc groups, thereby forming $3 \mathrm{~nm}$ fibrils which interact laterally to create "flat ribbons." RGD groups were added to increase cell attachment (Figure 2, in red) and these gels produce a viable 3D encapsulated cell culture with HDFa cells. As such, the scaffolds are suitable for assessment by various methods including fluorescence microscopy and the MTS assay (84). The cell gel constructs are formed by dissolving the peptide in DMSO followed by dilution in an aqueous solution at $\mathrm{pH} 10$ (Fmoc-FF) or pH 3 (Fmoc-RGD), followed by adjustment of the $\mathrm{pH}$ to physiological conditions. The solutions can then be mixed with cells in culture medium (87). The gel forms quickly $<1 \mathrm{~min}$ and has a $\mathrm{G}^{\prime}$ of around $780 \mathrm{~Pa}$ with the final stiffness of the gel being primarily dependent on the final $\mathrm{pH}$ (88). Within this system, addition of amino acids other than RGD were tested as well resulting in hydrogel constructs that were more suitable for some cell lines than others. For example, FmocLysine, Fmoc-Glutamic acid, or Fmoc-Serine constructs were able to grow human dermal fibroblasts but only Fmoc-Serine allowed for the growth of chondrocytes and 3T3 cells (89). Other stacking 


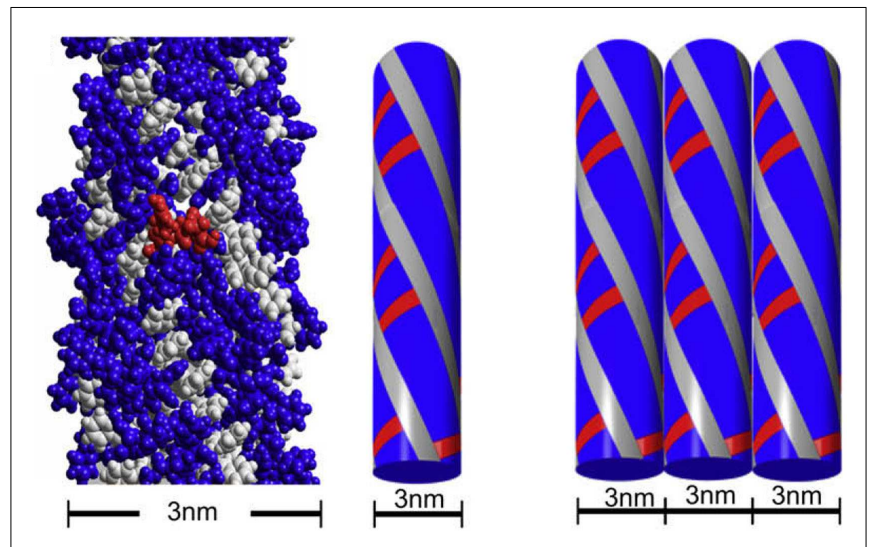

FIGURE 2 |The fibrillar structure of Fmoc-FF and Fmoc-RGD. Reprinted with permission from Ref. (84). Copyright 2009 Elsevier Ltd.

groups, naphthalene and benzyloxycarbonyl, in place of the Fmoc group have been shown to create fibrils that support chondrocyte growth (90). Changes to the sequence included different combinations of phenylalanine and RGD in order to avoid mixing of different peptides (91). Recently, work has been done to improve the biocompatibility of the gelation process by using glutathione to cleave a sulfide bond on the pregelator that would allow the peptide to gel avoiding the use of DMSO (92). Another group altered and improved gelation by halogenating the phenyl ring on phenylalanine, a scaffold that could be used to culture 3T3 cells after adding RGD to the system (72). Yet, other groups have added different amino acids to improve cell attachment and confirmed the importance of the RGD group (93). While Fmoc groups are not normally found in the ECM, these gels exhibit decent stiffness and appropriate rheology and have proven suitable as $3 \mathrm{D}$ cell culture scaffold.

\section{h9e}

h9e is a peptide hydrogel initially designed for drug delivery of a H1N1 vaccine (94) (Figure 3). It was designed by rationally combining functional native domains from the spider flagelliform silk protein and the trans-membrane segment of human muscle L-type calcium channel, resulting in a peptide with the sequence FLIVIGSIIGPGGDGPGGD $(95,96)$. h9e can produce a viable matrix for 3D encapsulation of MCF-7 cells (97), and has the unique property of displaying shear flow only when gelation is induced in the presence of calcium but not when calcium is absent. Calcium also increases the speed of gelation (98). To produce a matrix for cell encapsulation, the lyophilized peptide is dissolved into sodium bicarbonate and then added to cells in culture medium. Within $15 \mathrm{~min}$, the mixture can solidify into a gel with a final stiffness of $500 \mathrm{~Pa}$ (97). The gel has no apparent negative effect on cell viability but cells divide slower as compared to $2 \mathrm{D}$, an effect not uncommon in $3 \mathrm{D}$ culture constructs. Interestingly, 3D encapsulated cells displayed increased sensitivity to cisplatin compared to $2 \mathrm{D}$ cultures and the matrix is suitable for a variety of analytical methods including Western blotting, fluorescence microscopy, and trypan blue staining upon isolating the cells from the gel.

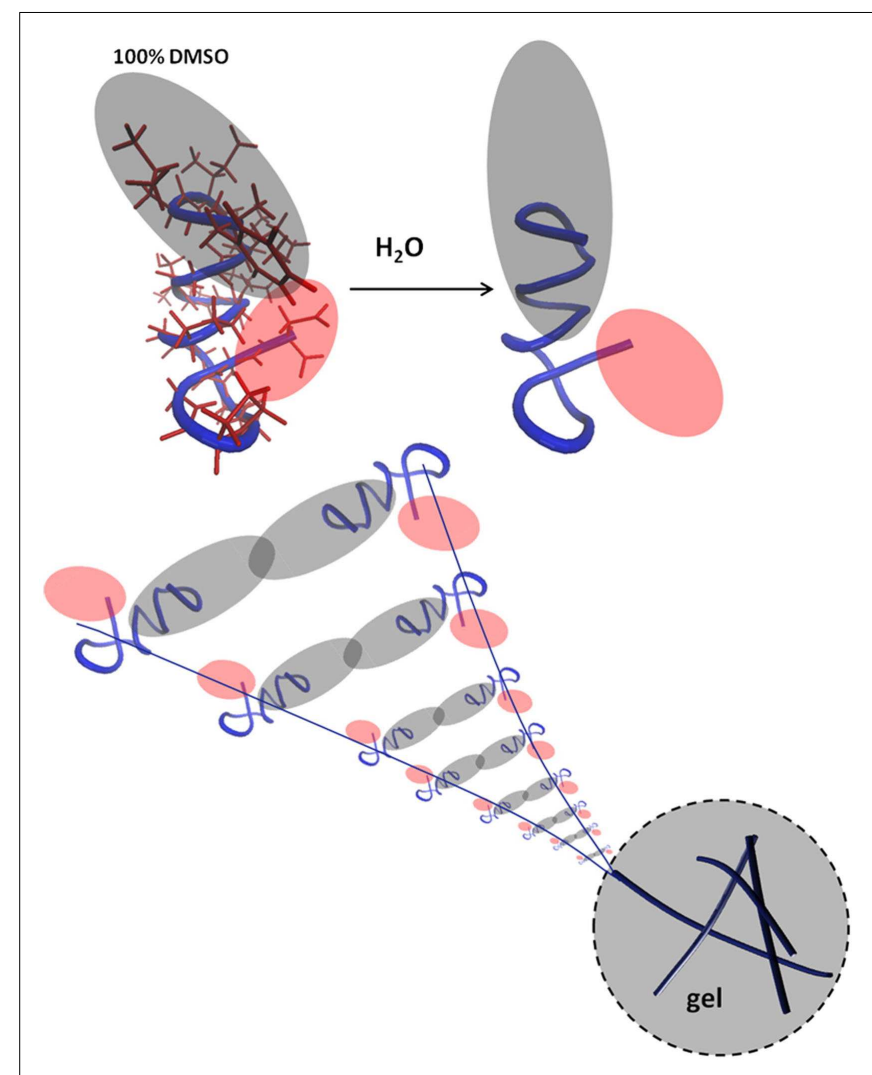

FIGURE 3 |The peptide interactions that form a fibril. Reprinted with permission from Ref. (98). Copyright 2012 Biophysical Society.

\section{FEFK AND FEFKEFK}

FEFK and FEFKEFK form a hydrogel upon a unique enzymatic interaction with a metalloproteinase (99) (Figure 4). FEFK is a short chain peptide that does not form a gel on its own but in the presence of the metalloproteinase thermolysine, the peptide is broken down and rebuilt into longer chains that do gel (100). This is a different gel strategy compared to most peptide gels which depend on pH, ionic salts, or light (101). The final makeup of the gel is determined by the initial concentration of FEFK, and the mechanical properties are determined by the initial enzyme concentration (102). Gelation can also be controlled by the temperature used to initiate the reaction $(103,104)$. To prepare the cell-gel constructs, FEFK is dissolved in PBS, loaded into a syringe, and the enzyme is added. After incubation for $5 \mathrm{~min}$, cells can be added and the solution is injected in a well, requiring frequent media change in the initial $1 \mathrm{~h}$ of incubation to remove the enzyme. The gel takes about $10 \mathrm{~min}$ for gelation and finishes around $2000 \mathrm{~Pa}$ $(105,106)$. The hydrogel construct has been used for successful culture of fibroblasts and osteoblasts and no negative effects of the enzyme used for gelation were observed although about $40 \%$ of the enzyme remained within the gel at day 7 (105). Multiple cell viability studies report biocompatibility of the gel but the most in depth biological investigation was on the ability of osteoblasts to mineralize the gel showing increased calcium phosphate deposits and an increase in gel stiffness as the cells deposit calcium and 


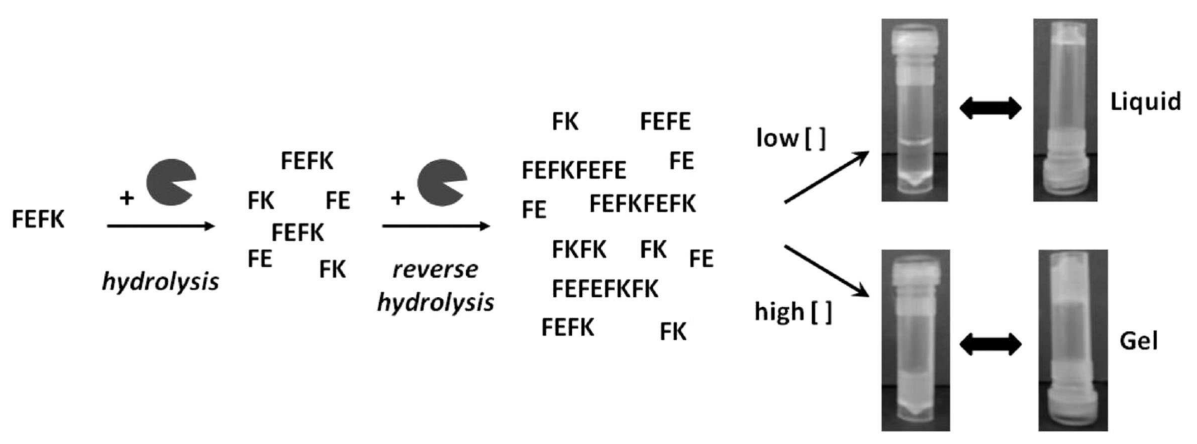

FIGURE 4 | Interaction between FEFK and enzyme. Reprinted with permission from Ref. (102). Copyright 2013 American Chemical Society.

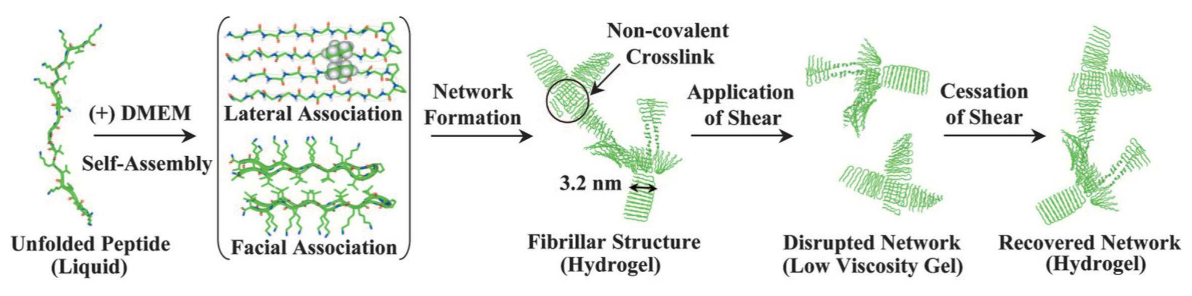

FIGURE 5 | MAX1 and MAX8 fibril formation. Reprinted with permission from Ref. (114). Copyright 2007 National Academy of Sciences.

extracellular proteins, indicating bone formation (106). The cellhydrogel constructs can be used for live dead staining and isolation of cells from the gel. Additional studies have shown that the peptide can be functionalized with polymers without affecting the gel (107).

\section{K(SL)3RG(SL)3KGRGDS}

$\mathrm{K}(\mathrm{SL}) 3 \mathrm{RG}(\mathrm{SL}) 3 \mathrm{KGRGDS}$ is an amphiphilic peptide with a nonpolar middle surrounded by charged side regions, called a multi domain peptide (108). It forms beta sheets in aqueous solution by dimerizing to protect the non-polar core (109). The fibers had a diameter of $6 \mathrm{~nm}$, expressed RGD for cell binding, and were susceptible to cleavage by cells (110). To form the cell-gel construct, the peptide was dissolved in water with sucrose and cells in PBS were added to the peptide solution starting the gelling process. To visualize cells, samples can be embedded and microtomed before being processed for microscopy (111). Cell viability assays revealed that addition of the RGD sequence slightly improved viability, but interestingly the viability was much more influenced by the location of the serines within the peptide sequence. In addition, incorporation of growth factors into the gel to improve culture conditions showed that addition of FGF improved the proliferation of fibroblasts but TGF- $\beta$ had the opposite effect (111). While studies in cancer cells are still lacking, using such a construct dental pulp stem cells were successfully cultured and the cells were able to break down the gel and build up their own ECM, demonstrating the capability to create an engineered dental pulp (111). Using this peptide as base, studies were performed to see how changing the non-polar core to amphiphilic rings would affect gelation. While the basic nanofibrous morphology was retained in all cases, particular core residues resulted in switching from antiparallel hydrogen bonding to parallel bonding. In some cases, this resulted in more brittle fibers but fibrils always formed (112). When the serines in the serine leucine repeats were changed to threonine, the hydrogel still formed and encapsulated cells proliferated and broke down the scaffold, but the cells on the threonine scaffold grew much slower, especially if RGD was missing (113).

\section{MAX1}

MAX1 is an amphiphilic peptide with the sequence VKVKVKVKVDPPT-KVEVKVKV (54) (Figure 5). Gelation is triggered by a combination of salt concentration, $\mathrm{pH}$, and temperature (114). These factors lead to charge screening which causes the peptide to fold into a beta hairpin, the hairpins then associate into fibrils forming the network through physical bonds (115). MAX1 gelation takes approximately $30 \mathrm{~min}$ to complete, which results in a heterogeneous cell distribution because the cells are able to sink through the gel. In order to ensure a homogenous cell distribution MAX8 was created by substituting a glutamic acid for a lysine, speeding up the gelation time to $1 \mathrm{~min}$ (114). To form a cell-gel construct, cells in serum-free medium are added to peptide dissolved in Hepes buffer and the construct is allowed to gelate before serum-containing medium is added to the culture. Using such a construct, mesenchymal stem cells, DAOY, Panc-1, and MG63 cells have been successfully cultured encapsulated within the gel (116, 117) (and our unpublished observations). The cell-hydrogel constructs can be assessed by fluorescence microscopy and MTT assays have been successfully performed. The fibrils have a $3.2 \mathrm{~nm} \times 2 \mathrm{~nm}$ cross section (115) and the stiffness is around $1000 \mathrm{~Pa}$, which can be controlled by changing the weight percent of the peptide and 
the speed of gelation which controls the number of branch points (118). MAX1 and MAX8 are shear thinning material allowing for gel injection while protecting its cargo (119). Thus, MAX8 can be used to deliver cells for therapy via syringe injecting while at the same time protecting the cells from shear forces (117). Furthermore, these hydrogels can be used for sustained delivery of active compounds including drugs. Studies have shown that encapsulated compounds may be protected from inactivation resulting in a consistent drug release over increased periods of time $(119,120)$ and in vivo biocompatibility has been demonstrated (116) (and our unpublished observations). The result is a highly customizable physical gel that shear thins and reheals. Gelation is triggered by physiological conditions allowing for easy culture setup without requiring the addition of harmful chemicals or organic reagents. It is mechanically robust with control over the storage modulus and a range of $500-10,000 \mathrm{~Pa}$, thereby providing a very versatile $3 \mathrm{D}$ culture scaffold.

\section{CONCLUSION}

The field of 3D cell culture is rapidly expanding due to new techniques and technologies that allow for this more complex culture system. It has resulted in new cell models that allow for the investigation of cellular phenotypes previously only seen in vivo. Much of the success is owed to the biocompatibility and bioactivity of natural materials and many current synthetic materials are designed by examining those found in nature. And while there is and will be a place for natural cell scaffolds in cellular investigation, it does not mean that the field needs to stop there. The advantages offered to cell culture by synthetic peptide scaffolds are great and will allow for in depth study of how cells interact with their environment and how the environment interacts with the cells. The biocompatibility and chemically defined nature of the materials results in a positive growth environment without the uncontrolled effects of unknown growth factors and proteins present. The synthetic nature of material synthesis allows for a consistent material without batch-to-batch variation, and it makes it simple to make variations on the scaffold as the researcher sees fit. All of these variables come together to give a cell culture system where the researcher has total control of the cellular environment and can trust that the results they are seeing are because of the changes they made. Having reliable, more in vivo like culture systems opens up a plethora of new possibilities in cancer research, from mimicking ECM environment to designing multi-cellular, tumor-like systems to developing culture systems that favor tumor stem cells. It is only a matter of time that the use of such complex platforms in drug discovery will result in novel lead compounds to support our quest to find a cure for the most aggressive and deadly cancers.

\section{ACKNOWLEDGMENTS}

Support was provided by the National Institute of General Medical Sciences of the National Institutes of Health Awards Number NIGMS-P20GM103464, the American Cancer Society Grant Number RSG-09-021-01-CNE, and The Nemours Foundation.

\section{REFERENCES}

1. Barretina J, Caponigro G, Stransky N, Venkatesan K, Margolin AA, Kim S, et al. The cancer cell line encyclopedia enables predictive modelling of anticancer drug sensitivity. Nature (2012) 483(7391):603-7. doi:10.1038/nature11003
2. Ning Y, Manegold PC, Hong YK, Zhang W, Pohl A, Lurje G, et al. Interleukin-8 is associated with proliferation, migration, angiogenesis and chemosensitivity in vitro and in vivo in colon cancer cell line models. Int J Cancer (2011) 128(9):2038-49. doi:10.1002/ijc.25562

3. Clarke R. Human breast cancer cell line xenografts as models of breast cancer. The immunobiologies of recipient mice and the characteristics of several tumorigenic cell lines. Breast Cancer Res Treat (1996) 39(1):69-86. doi:10.1007/BF01806079

4. Alva A, Slovin S, Daignault S, Carducci M, Dipaola R, Pienta K, et al. Phase II study of cilengitide (EMD 121974, NSC 707544) in patients with nonmetastatic castration resistant prostate cancer, NCI-6735. A study by the DOD/PCF prostate cancer clinical trials consortium. Invest New Drugs (2012) 30(2):749-57. doi:10.1007/s10637-010-9573-5

5. Hajdu SI. A note from history: landmarks in history of cancer, part 4. Cancer (2012) 118(20):4914-28. doi:10.1002/cncr.27509

6. Hajdu SI, Darvishian F. A note from history: landmarks in history of cancer, part 5. Cancer (2013) 119(8):1450-66. doi:10.1002/cncr.27889

7. Voskoglou-Nomikos T, Pater JL, Seymour L. Clinical predictive value of the in vitro cell line, human xenograft, and mouse allograft preclinical cancer models. Clin Cancer Res (2003) 9(11):4227-39.

8. Hirschberg E. Tissue culture in cancer chemotherapy screening. Cancer Res (1958) 18(8 Pt 1):869-78.

9. Hanahan D, Wagner EF, Palmiter RD. The origins of oncomice: a history of the first transgenic mice genetically engineered to develop cancer. Genes Dev (2007) 21(18):2258-70. doi:10.1101/gad.1583307

10. Scherer WF, Syverton JT, Gey GO. Studies on the propagation in vitro of poliomyelitis viruses. IV. Viral multiplication in a stable strain of human malignant epithelial cells (strain HeLa) derived from an epidermoid carcinoma of the cervix. J Exp Med (1953) 97(5):695-710. doi:10.1084/jem.97.5.695

11. Hongisto V, Jernstrom S, Fey V, Mpindi JP, Kleivi Sahlberg K, Kallioniemi $\mathrm{O}$, et al. High-throughput 3D screening reveals differences in drug sensitivities between culture models of JIMT1 breast cancer cells. PLoS One (2013) 8(10):e77232. doi:10.1371/journal.pone.0077232

12. Benya PD, Shaffer JD. Dedifferentiated chondrocytes reexpress the differentiated collagen phenotype when cultured in agarose gels. Cell (1982) 30(1):215-24. doi:10.1016/0092-8674(82)90027-7

13. Kleinman HK, Martin GR. Matrigel: basement membrane matrix with biological activity. Semin Cancer Biol (2005) 15(5):378-86. doi:10.1016/j.semcancer. 2005.05.004

14. Sheu MT, Huang JC, Yeh GC, Ho HO. Characterization of collagen gel solutions and collagen matrices for cell culture. Biomaterials (2001) 22(13):1713-9. doi:10.1016/S0142-9612(00)00315-X

15. Rehfeldt F, Brown AE, Raab M, Cai S, Zajac AL, Zemel A, et al. Hyaluronic acid matrices show matrix stiffness in $2 \mathrm{D}$ and $3 \mathrm{D}$ dictates cytoskeletal order and myosin-II phosphorylation within stem cells. Integr Biol (Camb) (2012) 4(4):422-30. doi:10.1039/c2ib00150k

16. Swift J, Ivanovska IL, Buxboim A, Harada T, Dingal PC, Pinter J, et al. Nuclear lamin-A scales with tissue stiffness and enhances matrix-directed differentiation. Science (2013) 341(6149):1240104. doi:10.1126/science.1240104

17. Ayala R, Zhang C, Yang D, Hwang Y, Aung A, Shroff SS, et al. Engineering the cell-material interface for controlling stem cell adhesion, migration, and differentiation. Biomaterials (2011) 32(15):3700-11. doi:10.1016/j.biomaterials. 2011.02.004

18. Tibbitt MW, Anseth KS. Hydrogels as extracellular matrix mimics for $3 \mathrm{D}$ cell culture. Biotechnol Bioeng (2009) 103(4):655-63. doi:10.1002/bit.22361

19. Montanez-Sauri SI, Beebe DJ, Sung KE. Microscale screening systems for 3D cellular microenvironments: platforms, advances, and challenges. Cell Mol Life Sci (2015) 72(2):237-49. doi:10.1007/s00018-014-1738-5

20. Pampaloni F, Reynaud EG, Stelzer EH. The third dimension bridges the gap between cell culture and live tissue. Nat Rev Mol Cell Biol (2007) 8(10):839-45. doi:10.1038/nrm2236

21. Nelson CM, Bissell MJ. Of extracellular matrix, scaffolds, and signaling: tissue architecture regulates development, homeostasis, and cancer. Annu Rev Cell Dev Biol (2006) 22:287-309. doi:10.1146/annurev.cellbio.22.010305. 104315

22. Beck JN, Singh A, Rothenberg AR, Elisseeff JH, Ewald AJ. The independent roles of mechanical, structural and adhesion characteristics of 3D hydrogels on the regulation of cancer invasion and dissemination. Biomaterials (2013) 34(37):9486-95. doi:10.1016/j.biomaterials.2013.08.077 
23. Hadjipanayi E, Mudera V, Brown RA. Close dependence of fibroblast proliferation on collagen scaffold matrix stiffness. J Tissue Eng Regen Med (2009) 3(2):77-84. doi:10.1002/term.136

24. O’Brien FJ, Harley BA, Yannas IV, Gibson LJ. The effect of pore size on cell adhesion in collagen-GAG scaffolds. Biomaterials (2005) 26(4):433-41. doi:10.1016/j.biomaterials.2004.02.052

25. Saha K, Keung AJ, Irwin EF, Li Y, Little L, Schaffer DV, et al. Substrate modulus directs neural stem cell behavior. Biophys J (2008) 95(9):4426-38. doi:10.1529/biophysj.108.132217

26. Wells RG. The role of matrix stiffness in regulating cell behavior. Hepatology (2008) 47(4):1394-400. doi:10.1002/hep.22193

27. Chen CS, Mrksich M, Huang S, Whitesides GM, Ingber DE. Geometric control of cell life and death. Science (1997) 276(5317):1425-8. doi:10.1126/science. 276.5317.1425

28. Yamada KM, Cukierman E. Modeling tissue morphogenesis and cancer in 3D. Cell (2007) 130(4):601-10. doi:10.1016/j.cell.2007.08.006

29. Aubin H, Nichol JW, Hutson CB, Bae H, Sieminski AL, Cropek DM, et al. Directed 3D cell alignment and elongation in microengineered hydrogels. Biomaterials (2010) 31(27):6941-51. doi:10.1016/j.biomaterials. 2010.05.056

30. Keenan TM, Folch A. Biomolecular gradients in cell culture systems. Lab Chip (2008) 8(1):34-57. doi:10.1039/B711887B

31. Derda R, Laromaine A, Mammoto A, Tang SK, Mammoto T, Ingber DE, et al. Paper-supported 3D cell culture for tissue-based bioassays. Proc Natl Acad Sci US A (2009) 106(44):18457-62. doi:10.1073/pnas.0910666106

32. Nyga A, Cheema U, Loizidou M. 3D tumour models: novel in vitro approaches to cancer studies. J Cell Commun Signal (2011) 5(3):239-48. doi:10.1007/ s12079-011-0132-4

33. Wright MH, Calcagno AM, Salcido CD, Carlson MD, Ambudkar SV, Varticovski L. Brcal breast tumors contain distinct CD44+/CD24- and CD133+ cells with cancer stem cell characteristics. Breast Cancer Res (2008) 10(1):R10. doi:10.1186/bcr 1855

34. Fey SJ, Wrzesinski K. Determination of drug toxicity using 3D spheroids constructed from an immortal human hepatocyte cell line. Toxicol Sci (2012) 127(2):403-11. doi:10.1093/toxsci/kfs122

35. Wrighton PJ, Klim JR, Hernandez BA, Koonce CH, Kamp TJ, Kiessling LL. Signals from the surface modulate differentiation of human pluripotent stem cells through glycosaminoglycans and integrins. Proc Natl Acad Sci U S A (2014) 111(51):18126-31. doi:10.1073/pnas.1409525111

36. Nucera C. Targeting thyroid cancer microenvironment: basic research and clinical applications. Front Endocrinol (2013) 4:167. doi:10.3389/fendo.2013.00167

37. Nucera C, Lawler J, Parangi S. BRAF(V600E) and microenvironment in thyroid cancer: a functional link to drive cancer progression. Cancer Res (2011) 71(7):2417-22. doi:10.1158/0008-5472.CAN-10-3844

38. Bosman FT, Stamenkovic I. Functional structure and composition of the extracellular matrix. J Pathol (2003) 200(4):423-8. doi:10.1002/path.1437

39. Kim JB. Three-dimensional tissue culture models in cancer biology. Semin Cancer Biol (2005) 15(5):365-77. doi:10.1016/j.semcancer.2005.05.002

40. Song HH, Park KM, Gerecht S. Hydrogels to model 3D in vitro microenvironment of tumor vascularization. Adv Drug Deliv Rev (2014) 7(9-80):19-29. doi:10.1016/j.addr.2014.06.002

41. Yan C, Pochan DJ. Rheological properties of peptide-based hydrogels for biomedical and other applications. Chem Soc Rev (2010) 39(9):3528-40. doi:10.1039/b919449p

42. Li Z, Deming TJ. Tunable hydrogel morphology via self-assembly of amphiphilic pentablock copolypeptides. Soft Matter (2010) 6(11):2546-51. doi:10.1039/b927137f

43. Sathaye S, Mbi A, Sonmez C, Chen Y, Blair DL, Schneider JP, et al. Rheology of peptide- and protein-based physical hydrogels: are everyday measurements just scratching the surface? Wiley Interdiscip Rev Nanomed Nanobiotechnol (2015) 7(1):34-68. doi:10.1002/wnan.1299

44. Weber LM, He J, Bradley B, Haskins K, Anseth KS. PEG-based hydrogels as an in vitro encapsulation platform for testing controlled beta-cell microenvironments. Acta Biomater (2006) 2(1):1-8. doi:10.1016/j.act1bio.2005.10.005

45. Techatanawat S, Surarit R, Suddhasthira T, Khovidhunkit SP. Type I collagen extracted from rat-tail and bovine Achilles tendon for dental application: a comparative study. Asian Biomed (2011) 5(6):787-98. doi:10.5372/1905-7415. 0506.111
46. Raeber GP, Lutolf MP, Hubbell JA. Molecularly engineered PEG hydrogels: a novel model system for proteolytically mediated cell migration. Biophys $J$ (2005) 89(2):1374-88. doi:10.1529/biophysj.104.050682

47. Baeva LF, Lyle DB, Rios M, Langone JJ, Lightfoote MM. Different molecular weight hyaluronic acid effects on human macrophage interleukin 1beta production. J Biomed Mater Res A (2014) 102(2):305-14. doi:10.1002/jbm.a.34704

48. Burdick JA, Prestwich GD. Hyaluronic acid hydrogels for biomedical applications. Adv Mater (2011) 23(12):H41-56. doi:10.1002/adma.201003963

49. Goubko CA, Basak A, Majumdar S, Cao X. Dynamic cell patterning of photoresponsive hyaluronic acid hydrogels. J Biomed Mater Res A (2014) 102(2):381-91. doi:10.1002/jbm.a.34712

50. Kraehenbuehl TP, Zammaretti P, Van der Vlies AJ, Schoenmakers RG, Lutolf MP, Jaconi ME, et al. Three-dimensional extracellular matrix-directed cardioprogenitor differentiation: systematic modulation of a synthetic cellresponsive PEG-hydrogel. Biomaterials (2008) 29(18):2757-66. doi:10.1016/ j.biomaterials.2008.03.016

51. Weber LM, Hayda KN, Haskins K, Anseth KS. The effects of cell-matrix interactions on encapsulated beta-cell function within hydrogels functionalized with matrix-derived adhesive peptides. Biomaterials (2007) 28(19):3004-11. doi:10.1016/j.biomaterials.2007.03.005

52. Horii A, Wang X, Gelain F, Zhang S. Biological designer self-assembling peptide nanofiber scaffolds significantly enhance osteoblast proliferation, differentiation and 3-D migration. PLoS One (2007) 2(2):e190. doi:10.1371/journal.pone. 0000190

53. Narmoneva DA, Oni O, Sieminski AL, Zhang S, Gertler JP, Kamm RD, et al. Self-assembling short oligopeptides and the promotion of angiogenesis. Biomaterials (2005) 26(23):4837-46. doi:10.1016/j.biomaterials.2005.01.005

54. Schneider JP, Pochan DJ, Ozbas B, Rajagopal K, Pakstis L, Kretsinger J. Responsive hydrogels from the intramolecular folding and self-assembly of a designed peptide. J Am Chem Soc (2002) 124(50):15030-7. doi:10.1021/ja027993g

55. Pathak A, Kumar S. Biophysical regulation of tumor cell invasion: moving beyond matrix stiffness. Integr Biol (Camb) (2011) 3(4):267-78. doi:10.1039/ c0ib00095g

56. Orgel JP, Persikov AV, Antipova O. Variation in the helical structure of native collagen. PLoS One (2014) 9(2):e89519. doi:10.1371/journal.pone.0089519

57. Glowacki J, Mizuno S. Collagen scaffolds for tissue engineering. Biopolymers (2008) 89(5):338-44. doi:10.1002/bip.20871

58. Kutschka I, Chen IY, Kofidis T, Arai T, von Degenfeld G, Sheikh AY, et al. Collagen matrices enhance survival of transplanted cardiomyoblasts and contribute to functional improvement of ischemic rat hearts. Circulation (2006) 114(1 Suppl):I167-73. doi:10.1161/CIRCULATIONAHA.105.001297

59. Yang XB, Bhatnagar RS, Li S, Oreffo RO. Biomimetic collagen scaffolds for human bone cell growth and differentiation. Tissue Eng (2004) 10(78):1148-59. doi:10.1089/ten.2004.10.1148

60. Karst W, Merker HJ. The differentiation behaviour of MDCK cells grown on matrix components and in collagen gels. Cell Differ (1988) 22(3):211-24. doi:10.1016/0045-6039(88)90013-9

61. Liu Y, Luo D, Liu S, Fu Y, Kou X, Wang X, et al. Effect of nanostructure of mineralized collagen scaffolds on their physical properties and osteogenic potential. J Biomed Nanotechnol (2014) 10(6):1049-60. doi:10.1166/jbn.2014.1794

62. Hughes CS, Postovit LM, Lajoie GA. Matrigel: a complex protein mixture required for optimal growth of cell culture. Proteomics (2010) 10(9):1886-90. doi:10.1002/pmic.200900758

63. Poincloux R, Collin O, Lizarraga F, Romao M, Debray M, Piel M, et al. Contractility of the cell rear drives invasion of breast tumor cells in $3 \mathrm{D}$ Matrigel. Proc Natl Acad Sci U S A (2011) 108(5):1943-8. doi:10.1073/pnas. 1010396108

64. Wong CC, Gilkes DM, Zhang H, Chen J, Wei H, Chaturvedi P, et al. Hypoxiainducible factor 1 is a master regulator of breast cancer metastatic niche formation. Proc Natl Acad Sci U S A (2011) 108(39):16369-74. doi:10.1073/pnas. 1113483108

65. Schmeisser A, Garlichs CD, Zhang H, Eskafi S, Graffy C, Ludwig J, et al. Monocytes coexpress endothelial and macrophagocytic lineage markers and form cord-like structures in matrigel under angiogenic conditions. Cardiovasc Res (2001) 49(3):671-80. doi:10.1016/S0008-6363(00)00270-4

66. Gill BJ, West JL. Modeling the tumor extracellular matrix: tissue engineering tools repurposed towards new frontiers in cancer biology. J Biomech (2014) 47(9):1969-78. doi:10.1016/j.jbiomech.2013.09.029 
67. Wallace DG, Rosenblatt J. Collagen gel systems for sustained delivery and tissue engineering. Adv Drug Deliv Rev (2003) 55(12):1631-49. doi:10.1016/j.addr. 2003.08.004

68. Desai BJ, Gruber HE, Hanley EN Jr. The influence of matrigel or growth factor reduced matrigel on human intervertebral disc cell growth and proliferation. Histol Histopathol (1999) 14(2):359-68.

69. Collier JH, Segura T. Evolving the use of peptides as components of biomaterials. Biomaterials (2011) 32(18):4198-204. doi:10.1016/j. biomaterials.2011.02.030

70. Branco MC, Sigano DM, Schneider JP. Materials from peptide assembly: towards the treatment of cancer and transmittable disease. Curr Opin Chem Biol (2011) 15(3):427-34. doi:10.1016/j.cbpa.2011.03.021

71. Li J, Gao Y, Kuang Y, Shi J, Du X, Zhou J, et al. Dephosphorylation of D-peptide derivatives to form biofunctional, supramolecular nanofibers/hydrogels and their potential applications for intracellular imaging and intratumoral chemotherapy. J Am Chem Soc (2013) 135(26):9907-14. doi:10.1021/ ja404215g

72. Wang Y, Zhang Z, Xu L, Li X, Chen H. Hydrogels of halogenated Fmoc-short peptides for potential application in tissue engineering. Colloids Surf B Biointerfaces (2013) 104:163-8. doi:10.1016/j.colsurfb.2012.11.038

73. Yang Z, Zhao X. A 3D model of ovarian cancer cell lines on peptide nanofiber scaffold to explore the cell-scaffold interaction and chemotherapeutic resistance of anticancer drugs. Int J Nanomedicine (2011) 6:303-10. doi:10.2147/IJN.S15279

74. Zhang S, Gelain F, Zhao X. Designer self-assembling peptide nanofiber scaffolds for 3D tissue cell cultures. Semin Cancer Biol (2005) 15(5):413-20. doi:10.1016/j.semcancer.2005.05.007

75. Zhang S, Lockshin C, Herbert A, Winter E, Rich A. Zuotin, a putative Z-DNA binding protein in Saccharomyces cerevisiae. EMBO J (1992) 11(10):3787-96.

76. Zhang S, Holmes TC, DiPersio CM, Hynes RO, Su X, Rich A. Selfcomplementary oligopeptide matrices support mammalian cell attachment. Biomaterials (1995) 16(18):1385-93. doi:10.1016/0142-9612(95)96874-Y

77. Luo Z, Yue Y, Zhang Y, Yuan X, Gong J, Wang L, et al. Designer D-form selfassembling peptide nanofiber scaffolds for 3-dimensional cell cultures. Biomaterials (2013) 34(21):4902-13. doi:10.1016/j.biomaterials.2013.03.081

78. Moradi F, Bahktiari M, Joghataei MT, Nobakht M, Soleimani M, Hasanzadeh G, et al. BD PuraMatrix peptide hydrogel as a culture system for human fetal Schwann cells in spinal cord regeneration. J Neurosci Res (2012) 90(12):2335-48. doi:10.1002/jnr.23120

79. Cheng TY, Chen MH, Chang WH, Huang MY, Wang TW. Neural stem cells encapsulated in a functionalized self-assembling peptide hydrogel for brain tissue engineering. Biomaterials (2013) 34(8):2005-16. doi:10.1016/j. biomaterials.2012.11.043

80. Sun L, Zhao X. A self-assembling peptide RADA16-I integrated with spider fibroin uncrystalline motifs. Int J Nanomedicine (2012) 7:571-80. doi:10.2147/ IJN.S27428

81. Jun S, Hong Y, Imamura H, Ha BY, Bechhoefer J, Chen P. Self-assembly of the ionic peptide EAK16: the effect of charge distributions on self-assembly. Biophys J (2004) 87(2):1249-59. doi:10.1529/biophysj.103.038166

82. Smith AM, Williams RJ, Tang C, Coppo P, Collins RF, Turner ML, et al. Fmoc-diphenylalanine self assembles to a hydrogel via a novel architecture based on $\pi-\pi$ interlocked $\beta$-sheets. Adv Mater Deerfield (2008) 20(1):37-41. doi:10.1002/adma.200701221

83. Orbach R, Adler-Abramovich L, Zigerson S, Mironi-Harpaz I, Seliktar D, Gazit E. Self-assembled Fmoc-peptides as a platform for the formation of nanostructures and hydrogels. Biomacromolecules (2009) 10(9):2646-51. doi:10.1021/bm900584m

84. Zhou M, Smith AM, Das AK, Hodson NW, Collins RF, Ulijn RV, et al. Selfassembled peptide-based hydrogels as scaffolds for anchorage-dependent cells. Biomaterials (2009) 30(13):2523-30. doi:10.1016/j.biomaterials.2009.01.010

85. Jayawarna V, Ali M, Jowitt TA, Miller AF, Saiani A, Gough JE, et al. Nanostructured hydrogels for three-dimensional cell culture through selfassembly of fluorenylmethoxycarbonyl-dipeptides. Adv Mater Deerfield (2006) 18(5):611-4. doi:10.1002/adma.200501522

86. Mahler A, Reches M, Rechter M, Cohen S, Gazit E. Rigid, self-assembled hydrogel composed of a modified aromatic dipeptide. Adv Mater Deerfield (2006) 18(11):1365-70. doi:10.1002/adma.200501765
87. Zhou M, Ulijn RV, Gough JE. Extracellular matrix formation in self-assembled minimalistic bioactive hydrogels based on aromatic peptide amphiphiles. J Tissue Eng (2014) 5:2041731414531593. doi:10.1177/2041731414531593

88. Raeburn J, Pont G, Chen L, Cesbron Y, Levy R, Adams DJ. Fmocdiphenylalanine hydrogels: understanding the variability in reported mechanical properties. Soft Matter (2012) 8(4):1168-74. doi:10.1039/c1sm06929b

89. Jayawarna V, Richardson SM, Hirst AR, Hodson NW, Saiani A, Gough JE, et al. Introducing chemical functionality in Fmoc-peptide gels for cell culture. Acta Biomater (2009) 5(3):934-43. doi:10.1016/j.actbio.2009.01.006

90. Jayawarna V, Smith A, Gough JE, Ulijn RV. Three-dimensional cell culture of chondrocytes on modified di-phenylalanine scaffolds. Biochem Soc Trans (2007) 35(Pt 3):535-7. doi:10.1042/BST0350535

91. Orbach R, Mironi-Harpaz I, Adler-Abramovich L, Mossou E, Mitchell EP, Forsyth VT, et al. The rheological and structural properties of Fmoc-peptidebased hydrogels: the effect of aromatic molecular architecture on self-assembly and physical characteristics. Langmuir (2012) 28(4):2015-22. doi:10.1021/ la204426q

92. Shi Y, Wang J, Wang H, Hu Y, Chen X, Yang Z. Glutathione-triggered formation of a Fmoc-protected short peptide-based supramolecular hydrogel. PLoS One (2014) 9(9):e106968. doi:10.1371/journal.pone.0106968

93. Modepalli VN, Rodriguez AL, Li R, Pavuluri S, Nicholas KR, Barrow CJ, et al. In vitro response to functionalized self-assembled peptide scaffolds for threedimensional cell culture. Biopolymers (2014) 102(2):197-205. doi:10.1002/bip. 22469

94. Li X, Galliher-Beckley A, Huang H, Sun X, Shi J. Peptide nanofiber hydrogel adjuvanted live virus vaccine enhances cross-protective immunity to porcine reproductive and respiratory syndrome virus. Vaccine (2013) 31(41):4508-15. doi:10.1016/j.vaccine.2013.07.080

95. Huang H, Sun XS. Rational design of responsive self-assembling peptides from native protein sequences. Biomacromolecules (2010) 11(12):3390-4. doi:10.1021/bm100894j

96. Huang H, Shi J, Laskin J, Liu Z, McVey DS, Sun XS. Design of a shearthinning recoverable peptide hydrogel from native sequences and application for influenza H1N1 vaccine adjuvant. Soft Matter (2011) 7(19):8905-12. doi:10.1039/c1sm05157a

97. Huang H, Ding Y, Sun XS, Nguyen TA. Peptide hydrogelation and cell encapsulation for 3D culture of MCF-7 breast cancer cells. PLoS One (2013) 8(3):e59482. doi:10.1371/journal.pone.0059482

98. Huang H, Herrera AI, Luo Z, Prakash O, Sun XS. Structural transformation and physical properties of a hydrogel-forming peptide studied by NMR, transmission electron microscopy, and dynamic rheometer. Biophys J (2012) 103(5):979-88. doi:10.1016/j.bpj.2012.07.027

99. Toledano S, Williams RJ, Jayawarna V, Ulijn RV. Enzyme-triggered selfassembly of peptide hydrogels via reversed hydrolysis. J Am Chem Soc (2006) 128(4):1070-1. doi:10.1021/ja056549l

100. Guilbaud JB, Vey E, Boothroyd S, Smith AM, Ulijn RV, Saiani A, et al. Enzymatic catalyzed synthesis and triggered gelation of ionic peptides. Langmuir (2010) 26(13):11297-303. doi:10.1021/la100623y

101. Williams RJ, Mart RJ, Ulijn RV. Exploiting biocatalysis in peptide self-assembly. Biopolymers (2010) 94(1):107-17. doi:10.1002/bip.21346

102. Guilbaud JB, Rochas C, Miller AF, Saiani A. Effect of enzyme concentration of the morphology and properties of enzymatically triggered peptide hydrogels. Biomacromolecules (2013) 14(5):1403-11. doi:10.1021/bm4000663

103. Yan H, Nykanen A, Ruokolainen J, Farrar D, Gough JE, Saiani A, et al. Thermoreversible protein fibrillar hydrogels as cell scaffolds. Faraday Discuss (2008) 139:71-84. doi:10.1039/b717748h

104. Yan H, Saiani A, Gough JE, Miller AF. Thermoreversible protein hydrogel as cell scaffold. Biomacromolecules (2006) 7(10):2776-82. doi:10.1021/bm0605560

105. Szkolar L, Guilbaud JB, Miller AF, Gough JE, Saiani A. Enzymatically triggered peptide hydrogels for 3D cell encapsulation and culture. JPept Sci (2014) 20(7):578-84. doi:10.1002/psc.2666

106. Castillo Diaz LA, Saiani A, Gough JE, Miller AF. Human osteoblasts within soft peptide hydrogels promote mineralisation in vitro. J Tissue Eng (2014) 5:2041731414539344. doi:10.1177/2041731414539344

107. Maslovskis A, Guilbaud JB, Grillo I, Hodson N, Miller AF, Saiani A. Selfassembling peptide/thermoresponsive polymer composite hydrogels: effect of peptide-polymer interactions on hydrogel properties. Langmuir (2014) 30(34):10471-80. doi:10.1021/la502358b 
108. Hartgerink JD, Beniash E, Stupp SI. Self-assembly and mineralization of peptide-amphiphile nanofibers. Science (2001) 294(5547):1684-8. doi:10. $1126 /$ science. 1063187

109. Dong H, Paramonov SE, Aulisa L, Bakota EL, Hartgerink JD. Self-assembly of multidomain peptides: balancing molecular frustration controls conformation and nanostructure. JAm Chem Soc (2007) 129(41):12468-72. doi:10.1021/ ja072536r

110. Galler KM, Aulisa L, Regan KR, D’Souza RN, Hartgerink JD. Self-assembling multidomain peptide hydrogels: designed susceptibility to enzymatic cleavage allows enhanced cell migration and spreading. J Am Chem Soc (2010) 132(9):3217-23. doi:10.1021/ja910481t

111. Galler KM, Hartgerink JD, Cavender AC, Schmalz G, D'Souza RN. A customized self-assembling peptide hydrogel for dental pulp tissue engineering. Tissue Eng Part A (2012) 18(1-2):176-84. doi:10.1089/ten.TEA.2011.0222

112. Bakota EL, Sensoy O, Ozgur B, Sayar M, Hartgerink JD. Self-assembling multidomain peptide fibers with aromatic cores. Biomacromolecules (2013) 14(5):1370-8. doi:10.1021/bm4000019

113. Kang MK, Colombo JS, D'Souza RN, Hartgerink JD. Sequence effects of selfassembling multidomain peptide hydrogels on encapsulated SHED cells. Biomacromolecules (2014) 15(6):2004-11. doi:10.1021/bm500075r

114. Haines-Butterick L, Rajagopal K, Branco M, Salick D, Rughani R, Pilarz M, et al. Controlling hydrogelation kinetics by peptide design for three-dimensional encapsulation and injectable delivery of cells. Proc Natl Acad Sci U S A (2007) 104(19):7791-6. doi:10.1073/pnas.0701980104

115. Hule RA, Nagarkar RP, Altunbas A, Ramay HR, Branco MC, Schneider JP, et al. Correlations between structure, material properties and bioproperties in selfassembled beta-hairpin peptide hydrogels. Faraday Discuss (2008) 139:251-64. doi:10.1039/b717616c

116. Haines-Butterick LA, Salick DA, Pochan DJ, Schneider JP. In vitro assessment of the pro-inflammatory potential of beta-hairpin peptide hydrogels. Biomaterials (2008) 29(31):4164-9. doi:10.1016/j.biomaterials.2008.07.009
117. Yan C, Mackay ME, Czymmek K, Nagarkar RP, Schneider JP, Pochan DJ. Injectable solid peptide hydrogel as a cell carrier: effects of shear flow on hydrogels and cell payload. Langmuir (2012) 28(14):6076-87. doi:10.1021/ la2041746

118. Branco MC, Nettesheim F, Pochan DJ, Schneider JP, Wagner NJ. Fast dynamics of semiflexible chain networks of self-assembled peptides. Biomacromolecules (2009) 10(6):1374-80. doi:10.1021/bm801396e

119. Branco MC, Pochan DJ, Wagner NJ, Schneider JP. The effect of protein structure on their controlled release from an injectable peptide hydrogel. Biomaterials (2010) 31(36):9527-34. doi:10.1016/j.biomaterials.2010.08.047

120. Altunbas A, Lee SJ, Rajasekaran SA, Schneider JP, Pochan DJ. Encapsulation of curcumin in self-assembling peptide hydrogels as injectable drug delivery vehicles. Biomaterials (2011) 32(25):5906-14. doi:10.1016/j.biomaterials.2011. 04.069

Conflict of Interest Statement: The authors declare that the research was conducted in the absence of any commercial or financial relationships that could be construed as a potential conflict of interest.

Received: 10 February 2015; accepted: 30 March 2015; published online: 20 April 2015. Citation: Worthington P, Pochan DJ and Langhans SA (2015) Peptide hydrogels versatile matrices for $3 D$ cell culture in cancer medicine. Front. Oncol. 5:92. doi: 10.3389/fonc.2015.00092

This article was submitted to Molecular and Cellular Oncology, a section of the journal Frontiers in Oncology.

Copyright (c) 2015 Worthington, Pochan and Langhans. This is an open-access article distributed under the terms of the Creative Commons Attribution License (CC BY). The use, distribution or reproduction in other forums is permitted, provided the original author(s) or licensor are credited and that the original publication in this journal is cited, in accordance with accepted academic practice. No use, distribution or reproduction is permitted which does not comply with these terms. 